\title{
Spousal violence and pregnancy termination among married women in Nigeria
}

\author{
Solanke Lukman Bola
}

Demography and Social Statistics. Obafemi Awolowo University Ile-Ife 220005, Nigeria

\begin{abstract}
Background: In Nigeria, the relationship between spousal violence and pregnancy termination had not been adequately explored.

Objectives: To assess the prevalence of spousal violence, and examine the relationship between spousal violence and pregnancy termination.

Methods: Data on spousal violence among ever married women was extracted from the 2013 Nigeria Demographic and Health Survey. The outcome variable is pregnancy termination. The explanatory variables were the type of spousal violence experienced by the women in the last 12 months preceding the survey. Descriptive statistical analysis and binary logistic regression were applied using stata version 12 .

Results: Results show that $13.8 \%$ of women had ever terminated pregnancy; $19.9 \%$ had ever experienced at least one type of spousal violence; and women who had ever terminated pregnancy had higher prevalence of all types of spousal violence. Women who had ever experienced spousal physical violence were $9 \%$ more likely to experience pregnancy termination (OR=1.09; CI: 1.03-2.86); and women who had ever experienced spousal emotional violence were 33\% more likely to experience pregnancy termination (OR=1.33; CI: 0.97-1.95).

Conclusions: Spousal violence is significantly related to pregnancy termination. Improving women's sexual and reproductive health in the country requires fresh initiatives that address spousal violence to further reduce women's exposure to pregnancy termination.
\end{abstract}

Keywords: Spousal violence, pregnancy termination, married women, Nigeria.

DOI: http://dx.doi.org/10.4314/ahs.v16i2.11

Cite as: Bola SL. Spousal violence and pregnancy termination among married women in Nigeria. Afri Health Sci 2016;16(2): 429440. bttp:/ / dx.doi.org/10.4314/abs.v16i2.11

\section{Introduction}

One hundred years of Nigerian nationhood (1914-2014) have accomplished little in terms of improving the health and well-being of women. Women's health particularly sexual and reproductive health remain greatly undermined by widespread socio-cultural practices that continue to treat Nigerian women mostly as inferior to men. One of these culturally sanctioned practices is wife battery which is now globally noted and discussed in the

\section{Corresponding author:}

Solanke Lukman Bola,

Demography and Social Statistics.

Obafemi Awolowo University

Ile-Ife. 220005

Nigeria

Tel: +2348036313463

Email: modebolasolanke@gmail.com context of spousal violence. Spousal violence is a type of gender-based violence that can occur among both heterosexual and same-sex partners. It refers to physical, sexual or psychological harm perpetrated by a current or former partner or spouse ${ }^{1}$. However, evidence abounds that physical violence is not only the dominant form of spousal violence, but is also the precursor of other forms of violence in intimate relationships ${ }^{2-3}$.

Studies have shown that women living with female partners experience less spousal violence compared with women living with male partners ${ }^{4}$ indicating that men are the key perpetrators of spousal violence. Recent evidence from a Demographic and Health Survey (DHS) 20002012 assessment of violence against women aged 15-49 years in 34 countries show that not less than $10 \%$ of ever married women surveyed experienced physical and/or sexual violence. The survey further reveals that in 6 countries, more than $10 \%$ of the women experienced violence during their most recent pregnancy ${ }^{5}$. 
In Nigeria, the 2008 Nigeria Demographic and Health Survey (NDHS) found that $22.4 \%$ of the surveyed women had experienced physical violence; $5.3 \%$ had experienced physical and sexual violence; and $29.3 \%$ had experienced physical or sexual violence. It further found that $5.1 \%$ of women experienced violence during pregnancy; and current husband/partners were the dominant perpetrators of physical and sexual violence against every married woman ${ }^{6}$. The most recent DHS in the country also found that among ever-married women, $14 \%$ had experienced spousal physical violence, $5 \%$ had experienced spousal sexual violence, and 19\% had experienced spousal emotional violence ${ }^{7}$. Prevalence of spousal violence thus continued unabated in the country in spite of nearly a decade of the design and implementation of National Gender Policy that mainly seeks to promote the enjoyment of women's fundamental human rights and sexual and reproductive health ${ }^{8}$.

Research over the decade has provided ample evidence of the negative effects of spousal violence on women's reproductive health. These include homicide, suicide, physical injuries, unwanted pregnancies, increased vulnerability to sexually transmitted infections (STIs) including HIV, abortion, gynaecological complaints, and low body mass index ${ }^{9-13}$.

Many studies have highlighted the relationship between spousal violence and other issues ${ }^{14-19}$. Some recent studies have also related spousal violence to pregnancy termination ${ }^{20-22}$. However, most of the studies linking spousal violence to pregnancy termination were not conducted in Nigeria. Hence, the relationship has not been adequately explored in the country. The current study addressed this limitation by assessing prevalence of spousal violence among women who had ever experienced pregnancy termination; and examining the relationship between spousal violence and pregnancy termination. By impeding women's physical, sexual, and reproductive health over a long period ${ }^{23}$, it is expected that spousal violence may influence pregnancy termination.

\section{Further literature}

Spousal violence exists in all countries though with varying degrees of prevalence. In a review of 50 populationbased studies conducted at various times in 36 countries between 1982 and 1999, it was found that among women who had ever been in an intimate relationship, physical assault on women by a male partner ranged from $10 \%$ in Philippines and Paraguay to $69 \%$ in Nicaragua ${ }^{24}$. These rates were similar to those reported in a multi- country study conducted in nine countries (Cambodia, Colombia, the Dominican Republic, Egypt, Haiti, India, Nicaragua, Peru, and Zambia). In the study, the proportion of women who had lifetime experience of spousal physical violence ranged from $16.4 \%$ in Cambodia to $40 \%$ in Colombia; spousal sexual violence ranged from 3.6\% in Cambodia to $17 \%$ in Haiti; and spousal emotional violence also ranged from $11.5 \%$ in Colombia to $29 \%$ in Nicaragua ${ }^{25}$.

Against the backdrop of growing international concern about violence against women, the WHO in 1997 initiated a multi-country study to assess the prevalence, health consequences, and associated risk factors of violence against women in ten countries (Bangladesh, Brazil, Ethiopia, Japan, Namibia, Peru, Samoa, Serbia and Montenegro, Thailand, and United Republic of Tanzania). It was found in the study that more of the surveyed women had experienced spousal physical violence compared with sexual or emotional violence. Among the countries studied, both physical and sexual violence were less prevalent in Japan compared with Bangladesh, Ethiopia, and Thailand where spousal sexual violence was reported to be more frequent than physical violence ${ }^{26}$.

The variation across countries in women's experience of spousal violence was further revealed by findings from a couples study conducted in ten demographic and health survey (DHS) countries (Bangladesh, Bolivia, Dominican Republic, Haiti, Kenya, Malawi, Moldova, Rwanda, Zambia, and Zimbabwe). In the study, the prevalence of spousal physical violence ranged from $15 \%$ in the Dominican Republic to $71 \%$ in Bangladesh which also had the highest rates of spousal sexual violence ${ }^{27}$. In another study involving men and women in Ghana and Uganda, higher experience of spousal violence among women than men was found. For instance in Uganda, $47.2 \%$ of women reported ever experiencing spousal physical violence compared with $19.1 \%$ of men who reported ever experiencing spousal physical violence. Similarly while $3.7 \%$ of the women had experienced physical and sexual violence only, fewer proportions of men $(0.5 \%)$ experienced physical and sexual violence ${ }^{28}$. 
In a recent couple study conducted in Kenya, Malawi, Rwanda, Zambia and Zimbabwe, it was found that among women, lifetime experience of spousal physical violence was lowest in Malawi (19.6\%) and highest in Rwanda (53.9\%); and spousal sexual violence ranges from $11.7 \%$ in Rwanda to $16.7 \%$ in $\mathrm{Zambia}^{29}$. These rates were comparable to lifetime experience of spousal violence reported in a study conducted in Nepal. In the study, it was found that among currently married women $28 \%$ had experienced spousal physical or sexual violence ${ }^{30}$.

In spite of evident cases of worldwide prevalence of spousal violence, studies have continued to maintain that large cases of spousal violence remain unreported due to wrongful perception of spousal violence as a private or family affair. In Nigeria, substantial proportion of women agreed that a male partner is justified in physically assaulting his wife ${ }^{31-32}$. Such perception or attitude more often than not encourages the under reporting of the incidence and prevalence of spousal violence. While prevalence of spousal violence even during pregnancy ${ }^{33}$ is not in doubt in many countries, however, there is insufficient knowledge about the relationship between spousal violence and pregnancy termination in Nigeria. In other climes, studies have provided substantial evidence that exposure to spousal violence is related to pregnancy termination ${ }^{34-36}$. In one of the few studies conducted in Nigeria, it was found that women exposed to spousal violence had higher likelihood of miscarriages, induced abortions and stillbirths ${ }^{37}$. Against the backdrop of women's poor sexual and reproductive health, it is expected that more studies will be conducted in the country to further determine the relationship between spousal violence and pregnancy termination.

\section{Materials and methods \\ Data source}

Data on spousal violence among ever married women was extracted from the 2013 NDHS. We analysed a weighted sample of 21,196 from the total of 38,948 women included in the survey having excluded women who were not included in the domestic violence module and those who were unmarried. Unmarried women were excluded from the study for two reasons. On the one hand, out of the 27,634 women selected for the domestic violence module in the 2013 NDHS, 21,196 women were ever married while 6,438 women were unmarried. Compari- son of the frequency of pregnancy termination among the two groups of women may be misleading because of the dominance of ever married women. On the other hand, the exclusion of unmarried women who never terminated a pregnancy further reduces the size of unmarried women which affected application of the multivariate analysis.

\section{Variables}

The outcome variable in the study is pregnancy termination which is dichotomised into 'ever' or 'never' experienced pregnancy termination. Pregnancy termination as measured in the study did not distinguish between spontaneous or induced abortion since both could be affected by spousal violence. It was captured in the NDHS by asking women whether they had ever had pregnancy termination or not. The key explanatory variables were the type of spousal violence experienced by the women in the last 12 months preceding the survey.

These are physical, sexual, and emotional violence, with all captured by a number of specific intimate partner violent act. Physical violence was based on women's experience of whether partner had ever: pushed, shook or threw something; slapped; punched with fist or something harmful; kicked or dragged; tried to strangle or burn; threatened with knives, gun or other weapons; and twisted her arm or pull her hair.

Sexual violence was based on women's experience of partner ever physically forcing her to have sex or other sexual acts when not wanted. Emotional violence was measured by women's experience of whether partner had ever: humiliated her; threatened her with harm; and insulted or made her feel bad. A number of background variables cutting across individual, relationship and community/ society were also measured. These include woman/partner's education, partner alcoholic consumption, childhood experience of domestic violence, household decision, household wealth, and employment status. These variables were selected for inclusion having been found to be correlates of pregnancy loss, induced abortion and spousal violence in previous studies ${ }^{12,21 \& 34}$.

\section{Statistical analysis}

All statistical analyses were performed using Stata sequel to applying standardised sample weights and adjusting standard errors for both clustering and stratification with 
the 'svyset' command. Frequency table was used to describe sample characteristics and pregnancy termination. The chi-square statistic was used to ascertain the relationship between spousal violence and the background variables. This was done with the view of removing non significant variable from the multivariate analysis. Binary logistic regression was performed to examine the influence of spousal violence on pregnancy termination. The logistic regression was replicated in two models with Model 1 including all the variables and Model 2 including only spousal violence.

\section{Limitation of the study}

In understanding the inference made in the study, it is important to note that our analysis did not distinguish be- tween spontaneous or induced abortion. This may exaggerate the number of pregnancy termination associated with spousal violence. Though, we excluded unmarried women in the analysis; the exclusion however does not in any way suggest that partner violence or pregnancy termination do not occur among unmarried women.

\section{Results}

Table 1 presents background characteristics of the respondents. Educational attainment is poor among the women. Nearly half of the respondents had no formal education. Among those with educational attainment, secondary education was the dominant educational level attained, while higher education was the least achieved among the women.

Table 1: Descriptive statistics of married women included in the domestic violence module, by selected background variables and pregnancy termination, NDHS, 2013

\begin{tabular}{|c|c|c|}
\hline Background variable & $\begin{array}{l}\text { Number of } \\
\text { women }\end{array}$ & Percentage \\
\hline \multicolumn{3}{|l|}{ Woman's Education } \\
\hline None & 9,980 & 47.1 \\
\hline Primary & 4,176 & 19.7 \\
\hline Secondary & 5,472 & 25.8 \\
\hline Higher & 1,568 & 7.4 \\
\hline \multicolumn{3}{|l|}{ Partner's Education } \\
\hline None & 8,410 & 39.7 \\
\hline Primary & 3,858 & 18.2 \\
\hline Secondary & 5,993 & 28.3 \\
\hline Higher & 2,935 & 13.8 \\
\hline \multicolumn{3}{|c|}{ Partner alcoholic consumption } \\
\hline Does not drink & 17,255 & 81.4 \\
\hline Drinks & 3,941 & 18.6 \\
\hline \multicolumn{3}{|c|}{ Childhood experience of domestic violence } \\
\hline Father never beat mother & 17,935 & 84.6 \\
\hline Father ever beat mother & 3,261 & 15.4 \\
\hline \multicolumn{3}{|l|}{ Household wealth index } \\
\hline Lowest & 9,193 & 43.4 \\
\hline Middle & 3,926 & 18.5 \\
\hline Highest & 8,077 & 38.1 \\
\hline \multicolumn{3}{|l|}{ Place of residence } \\
\hline Urban & 7,883 & 37.2 \\
\hline Rural & 13,313 & 62.8 \\
\hline \multicolumn{3}{|c|}{ Participation in Household Decision } \\
\hline Joint dominance & 8,725 & 41.2 \\
\hline Male dominance & 12,471 & 58.8 \\
\hline \multicolumn{3}{|l|}{ Employment status } \\
\hline Woman not working & 6,327 & 29.8 \\
\hline Woman working & 14,869 & 70.2 \\
\hline \multicolumn{3}{|l|}{ Pregnancy Termination } \\
\hline Never terminated pregnancy & 18,277 & 86.2 \\
\hline Ever terminated pregnancy & 2,919 & 13.8 \\
\hline Total & 21,196 & 100.0 \\
\hline
\end{tabular}

Source: 2013 NDHS 
The pattern of educational attainment by partner's education showed no significant variation from the distribution of women by educational attainment. More than onethird of the women's husbands/partners had no formal education with secondary education been the dominant educational level attained among the partners. Less than two-fifths of the women reported that their husband/ partner did not consume alcohol. Majority of the respondent had no childhood experience of domestic violence. More than one-third of the women were either in the lower or highest wealth groups. Slightly more than two- thirds are currently working with most of them resident in rural parts of the country. For more than half of the respondents, household decisions were male dominated. Majority of the sampled women had not experienced pregnancy termination. When pregnancy termination was disaggregated based on the six geo-political zones of the country, pregnancy termination experience was higher among Southern women than Northern women (Table 2). The variations in the rates of termination of pregnancy across the geo-political zones was statistically significant $\left(\chi^{2}=13.7, \mathrm{p}<0.05\right)$.

\section{Table 2: Distribution of married women who had ever experienced pregnancy termination by geo-political zones, NDHS, 2013}

\begin{tabular}{|c|c|c|c|c|c|c|}
\hline Geo-political zone & \multicolumn{2}{|c|}{$\begin{array}{l}\text { Ever Experienced } \\
\text { Number } \% \\
\end{array}$} & \multicolumn{2}{|c|}{$\begin{array}{l}\text { Never Experienced } \\
\text { Number } \%\end{array}$} & \multicolumn{2}{|l|}{ Total } \\
\hline North Central (NC) & 291 & 10.0 & 2,638 & 90.0 & 2,929 & 13.8 \\
\hline North East (NE) & 522 & 15.0 & 2,954 & 85.0 & 3,476 & 16.4 \\
\hline North West (NW) & 823 & 11.0 & 6,696 & 89.0 & 7,519 & 35.5 \\
\hline South East (SE) & 356 & 19.0 & 1,514 & 81.0 & 1,870 & 8.8 \\
\hline South South (SS) & 349 & 16.0 & 1,833 & 84.0 & 2,182 & 10.3 \\
\hline South West (SW) & 578 & 18.0 & 2,642 & 82.0 & 3,220 & 15.2 \\
\hline Total & 2,919 & 13.8 & 18,227 & 86.2 & 21,196 & 100.0 \\
\hline Statistic & $\mathrm{Df}=5$ & & $=13.7$ & & 0.05 & \\
\hline
\end{tabular}

Source: Author analysis based on 2013 NDHS

Table 3 presents the prevalence of spousal violence among the sampled women as well as the differentials of spousal violence by pregnancy termination experience. Irrespective of pregnancy termination experience, the dominant type of spousal physical violence was being slapped by a partner $(8.2 \%)$. The least common types of spousal physical violence were spousal attempt to ever strangle or burn the female partner, and spouse attempt to ever threaten female partner with knives, guns or other weapons with each type accounting for a proportion of $0.7 \%$. After combining all types of spousal physical vio- lence into a composite spousal physical violence, results show that $9.9 \%$ of the women had ever experienced at least one type of spousal physical violence. Analysis by pregnancy termination experience reveals that women who had ever terminated a pregnancy consistently had higher prevalence of all types of spousal physical violence compared with those who have never terminated a pregnancy. For instance, $14.8 \%$ of women who had ever experienced a pregnancy termination had also experienced at least one type of spousal physical violence compared with 9.1\% who had never experienced a pregnancy termination. 
Table 3: Distribution of married women who had ever experienced various forms of spousal violence in the last twelve months preceding the survey by

Pregnancy termination, NDHS, 2013

\begin{tabular}{|c|c|c|c|c|}
\hline Type of spousal violence & $\begin{array}{l}\text { Never } \\
\text { terminated } \\
\text { pregnancy } \\
\text { Number } \\
(\%) \\
\end{array}$ & $\begin{array}{l}\text { Ever } \\
\text { terminated } \\
\text { pregnancy } \\
\text { Number } \\
(\%) \\
\end{array}$ & $\begin{array}{l}\text { Total } \\
\text { Number }(\%)\end{array}$ & Statistic \\
\hline \multicolumn{5}{|l|}{ Physical violence } \\
\hline $\begin{array}{l}\text { Spouse ever pushed, shook or threw } \\
\text { something }\end{array}$ & $775(4.2)$ & $219(7.5)$ & $994(4.7)$ & $\chi^{2}=33.0 *$ \\
\hline Spouse ever slapped & $1,374(7.5)$ & $361(12.4)$ & $1,735(8.2)$ & $\chi^{2}=35.7 *$ \\
\hline $\begin{array}{l}\text { Spouse ever punched with fist or } \\
\text { something harmful }\end{array}$ & $374(2.1)$ & $125(4.3)$ & $499(2.4)$ & $\chi^{2}=31.3 *$ \\
\hline Spouse ever kicked or dragged & $597(3.3)$ & $153(5.2)$ & $750(3.5)$ & $\chi^{2}=20.6^{*}$ \\
\hline Spouse ever tried to strangle or burn & $90(0.5)$ & $51(1.8)$ & $141(0.7)$ & $\chi^{2}=45.6^{*}$ \\
\hline $\begin{array}{l}\text { Spouse ever threatened with knive, gun or } \\
\text { other weapons }\end{array}$ & $109(0.6)$ & $47(1.6)$ & $156(0.7)$ & $\chi^{2}=22.1 *$ \\
\hline $\begin{array}{l}\text { Spouse ever twisted her arm or pull her } \\
\text { hair }\end{array}$ & $341(1.9)$ & $129(4.4)$ & $470(2.2)$ & $\chi^{2}=42.6^{*}$ \\
\hline At least one type of physical violence & $1,655(9.1)$ & $431(14.8)$ & $2,087(9.9)$ & $\chi^{2}=43.1 *$ \\
\hline \multicolumn{5}{|l|}{ Sexual violence } \\
\hline $\begin{array}{l}\text { Spouse ever physically forced sex when } \\
\text { not wanted }\end{array}$ & $571(3.1)$ & $160(5.5)$ & $731(3.5)$ & $\chi^{2}=23.9 *$ \\
\hline $\begin{array}{l}\text { Spouse forced other sexual acts when not } \\
\text { wanted }\end{array}$ & $225(1.2)$ & $58(2.0)$ & $283(1.3)$ & $\chi^{2}=6.3 *$ \\
\hline At least one type of sexual violence & $647(3.5)$ & $170(5.8)$ & $817(3.9)$ & $\chi^{2}=19.9 *$ \\
\hline \multicolumn{5}{|l|}{ Emotional violence } \\
\hline Spouse ever humiliated her & $1,398(7.6)$ & $368(12.6)$ & $1,766(8.3)$ & $\chi^{2}=38.2 *$ \\
\hline Spouse ever threatened her with harm & $740(4.1)$ & $195(6.7)$ & $935(4.4)$ & $\chi^{2}=21.9 *$ \\
\hline Spouse ever insult or make feel bad & $2,194(12.0)$ & $564(19.3)$ & $2,759(13.0)$ & $\chi^{2}=54.6^{*}$ \\
\hline At least one type of emotional violence & $2,701(14.8)$ & $687(23.6)$ & $3,388(16.0)$ & $\chi^{2}=65.2 *$ \\
\hline \multicolumn{5}{|l|}{ Other types } \\
\hline $\begin{array}{l}\text { At least one type of physical and sexual } \\
\text { violence }\end{array}$ & $1,942(10.6)$ & $499(17.1)$ & $2,441(11.5)$ & $\chi^{2}=48.2 *$ \\
\hline $\begin{array}{l}\text { At least one type of physical and } \\
\text { emotional violence }\end{array}$ & $3,252(17.8)$ & $799(27.4)$ & $4,052(19.1)$ & $\chi^{2}=72.6^{*}$ \\
\hline At least one type of spousal violence & $3,380(18.5)$ & $829(28.4)$ & $4,209(19.9)$ & $\chi^{2}=75.1 *$ \\
\hline
\end{tabular}

Source: Author analysis based on 2013 NDHS, *p<0.05

Sexual violence was least reported among the respondents compared with physical or emotional violence. Analysis by pregnancy termination experience showed that women who had ever experienced pregnancy termination had been more sexually abused by their male partners compared with those who had never experienced pregnancy termination. When the two types of spousal sexual violence were combined, only $3.9 \%$ of the respondents had ever been forced to sex or other sexual acts by the male partners. Irrespective of pregnancy termination experience, the dominant type of spousal emotional violence was being insulted or made to feel bad by the male partner $(13.0 \%)$. The least common type of spousal emotional violence was being ever threatened with harm by a male partner (4.4\%). Analysis by pregnancy termination experience revealed that women who had ever terminated a pregnancy consistently had higher prevalence of all types of spousal emotional violence compared with those who have never terminated a pregnancy. After combining all types of spousal emotional violence into a composite spousal emotional violence, result showed that $16.0 \%$ of the women had ever experienced at least one type of spousal emotional violence. Overall, 19.9\% of the women had experienced at least one type of spousal violence. Disaggregated data of spousal violence revealed that major forms of spousal violence were dominant in the Southern region particularly in the South East geopolitical zone (Table 4). 
Table 4: Percentage distribution of married women who had ever experiences various forms of spousal violence in the last twelve months preceeding the survey by geo-political zone, NDHS, 2013

\begin{tabular}{|l|l|l|l|l|l|l|l|l|}
\hline & \multicolumn{7}{|c|}{ Geo-political zone } & \\
Type of spousal violence & NC & \multicolumn{1}{|c|}{ NE } & \multicolumn{1}{|c|}{ SE } & SS & SW & Total \\
\hline At least one type of physical violence & 13.8 & 10.7 & 3.6 & 14.6 & 17.1 & 12.1 & 9.9 \\
\hline At least one type of sexual violence & 4.4 & 10.3 & 1.3 & 4.6 & 4.6 & 1.4 & 3.9 \\
\hline At least one type of emotional violence & 21.5 & 23.2 & 8.4 & 26.0 & 18.5 & 13.3 & 16.0 \\
\hline At least one type of physical and sexual violence & 15.0 & 16.6 & 4.5 & 15.5 & 18.1 & 12.5 & 11.5 \\
\hline At least one type of physical and emotional violence & 25.1 & 26.5 & 9.6 & 28.7 & 24.3 & 18.8 & 19.1 \\
\hline At least one type of spousal violence & 25.7 & 28.9 & 10.0 & 29.0 & 25.1 & 19.0 & 19.9 \\
\hline
\end{tabular}

Source: 2013 NDHS

Table 5 presents the results of chi-square tests performed to examine the relationship between the background variables and spousal violence. With the exclusion of place of residence, all the variables were significantly associated with spousal physical and emotional violence. However, only three of the selected variables (partner's education, partner's alcoholic consumption, and household wealth) were significantly associated with spousal sexual violence.

Table 5: Association of selected background variables with spousal violence

\begin{tabular}{|l|l|l|l|}
\hline Background variable & $\begin{array}{l}\text { Physical } \\
\text { violence } \\
\chi^{2} \text {-value }\end{array}$ & $\begin{array}{l}\text { Sexual } \\
\text { violence } \\
\chi^{2} \text {-value }\end{array}$ & $\begin{array}{l}\text { Emotional } \\
\text { violence } \\
\chi^{2} \text {-value }\end{array}$ \\
\hline Woman's education & $65^{* *}$ & $5.4^{\mathrm{NS}}$ & $30^{* *}$ \\
\hline Partner's education & $552^{* *}$ & $100^{* *}$ & $260^{* *}$ \\
\hline Partner alcoholic consumption & $188^{* *}$ & $92^{* *}$ & $225^{* *}$ \\
\hline Childhood experience of violence & $85^{* *}$ & $5^{\mathrm{NS}}$ & $37^{* *}$ \\
\hline Male dominance of household decision & $7^{* *}$ & $0.7^{\mathrm{NS}}$ & $86^{* *}$ \\
\hline Economic stress & $48^{* *}$ & $0.5^{\mathrm{NS}}$ & $29^{* *}$ \\
\hline Household wealth & $10^{* *}$ & $9.0^{*}$ & $7.2^{*}$ \\
\hline Place of residence & $0.9^{\mathrm{NS}}$ & $5.0^{\mathrm{NS}}$ & $2^{\mathrm{NS}}$ \\
\hline
\end{tabular}
$\mathrm{p}<0.05^{* *} \mathrm{p}<0.01{ }^{\mathrm{NS}}$ Non Significant

Table 6 presents results of association between spousal violence and pregnancy termination using multivariate logistic regression. In Model 1, women who had ever experienced spousal physical violence were $9 \%$ more likely to experience pregnancy termination than women who had never experienced spousal physical violence $(\mathrm{OR}=1.09$, $\mathrm{p}<0.05)$. The likelihood of pregnancy termination was $8 \%$ higher among those who had experienced spousal sexual violence $(\mathrm{OR}=1.08, \mathrm{p}<0.05)$ than women who had never experienced spousal sexual violence. Women who had ever experienced emotional violence were 33\% more likely to experience pregnancy termination than women 
who had never experienced spousal emotional violence $(\mathrm{OR}=1.33, \mathrm{p}<0.05)$. Similarly, the odds of pregnancy termination were consistently higher for women with exposure to at least one specific form of spousal violence or at least one type of spousal violence. After controlling for the effects of background variables in Model 2, all forms of spousal violence remain consistent predictors of pregnancy termination.

Table 6: Binary logistic regression analyses identifying spousal violence and background characteristics associated with ever having experienced pregnancy termination

\begin{tabular}{|c|c|c|c|c|}
\hline \multirow[b]{2}{*}{ Variable } & \multicolumn{2}{|c|}{ Model 1} & \multicolumn{2}{|c|}{ Model 2} \\
\hline & Odds Ratio & $95 \%$ CI & Odds Ratio & $95 \%$ CI \\
\hline \multicolumn{5}{|l|}{ Physical violence } \\
\hline Never experience & Ref. & Ref. & Ref. & Ref. \\
\hline Ever experience & $1.09 * *$ & $1.03-2.86$ & $1.26 * *$ & $0.77-2.07$ \\
\hline \multicolumn{5}{|l|}{ Sexual violence } \\
\hline Never experience & Ref. & Ref. & Ref. & Ref. \\
\hline Ever experience & $1.08 * *$ & $0.95-1.39$ & $1.04 *$ & $0.62-2.78$ \\
\hline \multicolumn{5}{|c|}{ Emotional violence } \\
\hline Never experience & Ref. & Ref. & Ref. & Ref. \\
\hline Ever experience & $1.33 * *$ & $0.97-1.95$ & $1.42 * *$ & $1.03-1.57$ \\
\hline \multicolumn{5}{|l|}{ Physical/sexual } \\
\hline Never experience & Ref. & Ref. & Ref. & Ref. \\
\hline Ever experience & $1.04 *$ & $1.02-1.75$ & $1.26^{* *}$ & $0.98-1.28$ \\
\hline \multicolumn{5}{|c|}{ Physical/sexual/emotional } \\
\hline Never experience & Ref. & Ref. & Ref. & Ref. \\
\hline Ever experience & $1.49^{* *}$ & $1.02-1.55$ & $1.63 * *$ & 1.06-1.85 \\
\hline \multicolumn{5}{|l|}{ Partner education } \\
\hline None & Ref. & Ref. & na & na \\
\hline Primary & $0.74 * *$ & $0.61-0.88$ & na & na \\
\hline Secondary & $0.89^{\mathrm{NS}}$ & $0.76-1.05$ & na & na \\
\hline Higher & $0.73 * *$ & $0.60-0.89$ & na & na \\
\hline \multicolumn{5}{|c|}{ Partner alcoholic drink } \\
\hline Does not drink & Ref. & Ref. & na & na \\
\hline Drinks & $1.73 * *$ & 0.64-1.84 & na & na \\
\hline \multicolumn{5}{|l|}{ Wealth index } \\
\hline Lowest & Ref. & Ref. & na & na \\
\hline Middle & $0.95^{\mathrm{NS}}$ & $0.78-1.14$ & na & na \\
\hline Highest & $0.79 *$ & $0.68-0.93$ & na & na \\
\hline
\end{tabular}

${ }^{*} \mathrm{p}<0.05 * * \mathrm{p}<0.01$; 'Ref' means reference category, 'na' means not available 


\section{Discussion}

In this study, we further assessed the prevalence of spousal violence and examined its relationship with pregnancy termination using the most recent DHS in Nigeria. The use of Nationally representative sample in the study enhances the validity and analysis of the concepts measured in the study. We excluded unmarried women from the analysis and were unable to separate spontaneous and deliberate pregnancy termination in the study. These may not only under report the extent of pregnancy termination among women in the country, but also prevent assessment of the specific relationships between spousal violence and the two types of pregnancy termination. Our analysis thus relates to the prevalence of pregnancy termination irrespective of types among married women experiencing or not experiencing spousal violence in the country. In spite of these limitations, findings from the study are comparable to findings in existing studies.

Overall, $19.9 \%$ of the women had experienced at least one type of spousal violence, and $13.8 \%$ of the women had experienced at least one pregnancy termination. The prevalence of spousal violence as found in this study is comparable with the range of prevalence found elsewhere ${ }^{26-28,33}$. However, the extent of spousal violence found in the current study differs markedly from findings in a recent study where more than a quarter of the women experienced at least one type of spousal physical violence compared with the one-tenth reported in the current study. The prevalence of sexual violence and other types of spousal violence were also found to be lower than the prevalence found in the study ${ }^{34}$. This variation may be explained by under reporting of spousal violence in Nigeria and further points to the need to develop means of encouraging women to speak up about spousal violence in the country.

The $13.8 \%$ prevalence of termination of pregnancy found in the study also contrasts with the Bangladeshi study where $21 \%$ of women surveyed have ever had a pregnancy termination. The proportion is however higher compared with the $5.8 \%$ prevalence of pregnancy termination in the last five years preceding the Bangladeshi study $^{34}$. Our findings confirm that women who experience spousal violence have elevated risk of pregnancy termination as found in an earlier Nigerian study. For instance, we found $5.8 \%$ and $3.5 \%$ prevalence of spousal sexual violence respectively among women who experi- enced and never experienced pregnancy termination consistent with the $6 \%$ and $3 \%$ found in the Nigerian study ${ }^{37}$.

The study provided additional evidence that women's education, partner's education, partner's alcoholic consumption, and childhood experience of domestic violence were among the multiple factors that predisposed women to spousal violence. Though, women's experience of pregnancy termination in Nigeria is usually under reported due to the existing law in the country which criminalises all pregnancy termination not connected to saving either the life of the mother or the unborn child, however, based on the number of women who reported to have ever terminated a pregnancy, we found in consonance with earlier findings ${ }^{20-22,36}$ that spousal violence is significantly associated with pregnancy termination.

Women who had ever had a pregnancy termination were found to have higher experience of all types of spousal violence indicating that spousal violence may aid increase in the likelihood of pregnancy termination among women.

It is easy to speculate why spousal violence influences women's demand for pregnancy termination since studies $^{20-22}$ have established that partner violence leads to unprotected sex and unwanted pregnancy that may increase the demand for both legal and induced abortion.

In a country like Nigeria where spousal violence has not attracted serious legal sanctions, the prevalence of spousal violence may continue unabated with more likelihood of induced abortion and its associated consequences for women's sexual and reproductive health in the country. Considering the fact that most women in violent relationship may not necessarily desire to quit such relationships, it is easy to speculate that women in such situation may go through pregnancy termination more than once since spousal violence particularly physical or sexual violence more often than not occurs not once, but continuously and over a long period of time. This is an additional reason why policies promoting universal access to contraceptives in the country must be redesigned to target more socio-cultural issues affecting women's health in the country. The demand for pregnancy termination is likely to reduce among women experiencing spousal violence if they have access to effective modern contraceptives. Future studies may identify more socio-cultural correlates 
of women's reproductive health by augmenting data from the Nationally representative sample with data generated from qualitative studies.

Spousal violence in the country continues to endanger women's health mainly due to the near absence of laws on domestic violence. As noted in the 2006 National Gender Policy, spousal violence particularly spousal physical violence is not recognised as a serious crime in the country unless it leads to grievous hurt defined as emasculation, permanent loss of sight, ability to hear or speak, facial disfigurement, deprivation of any member joint, bone fracture or tooth dislocation. The 2006 National Gender Policy may therefore fail to improve women's sexual and reproductive health in the country if not complimented by the enactment of adequate laws that protect the physical integrity of women's body and reduces their vulnerability to pregnancy termination. The contemporary challenge for the Nigerian Nation is therefore to ensure that within the first decade of the next one hundred years, legal reforms are pursued with new vigor. Women in the country must be fully mobilised to recognize sexual and reproductive rights as basic human rights that must be respected by all men particularly men in intimate relationships. However, this basic right may remain unenforceable even in the next one hundred years if adequate laws are not enacted. In the interim, improving educational opportunities among women in the country will go a long way to improve the reproductive health and general wellbeing of women in the country. The current situation of large proportions of uneducated women particularly in the Northern region of the country may continue to encourage the acceptance of spousal violence as a 'domestic affair' between partners.

\section{Conclusion}

This study affirms that a relationship exists between spousal violence and pregnancy termination. Improving women's sexual and reproductive health in the country requires fresh initiatives that address spousal violence to further reduce women's exposure to pregnancy termination. It is suggested that the National Assembly expedite actions on the enactment of laws protecting women's sexual and reproductive health. Non government actors such as women groups must step up actions for mobilising women to demand total elimination of all forms of spousal violence in the country.

\section{Acknowledgements}

The author appreciates and thanks the National Population Commission (NPC) [Nigeria], ICF

International and MEASURE DHS Project for making the datasets available for use.

\section{Conflict of interest}

The author declares no conflict of interest

\section{References}

1. Saltzman IE, Fanslow JL, McMahon PM, Shelley GA. (2002). Intimate Partner Violence Surveillance: uniform definition and recommended data elements. Centers for Disease Control and Prevention, National Center for Injury Prevention and Control.

2. Heise L, Ellsberg M, Gottmoeller M. (2002). A global overview of gender-based violence. International Journal of Gynecology and Obstetrics. 78(Suppl. 1):s5-s14.

3. United Nations (2011). Violence against Women. UN Department of Public Information. http://www.un.org/ en/women/endviolence/pdf/pressmaterials/unitethesituation-en.pdf, etrieved June 27th, 2013.

4. Black MC, Basile KC, Breiding MJ, Smith SG, Walters ML, Merrick MT, Chen J, Stevens MR. (2011). The National Intimate Partner and Sexual Violence Survey (NISVS): 2010 Summary Report. Atlanta, GA: National Center for Injury Prevention and Control, Centers for Disease Control and Prevention.

5. Head SK, Zweimueller S, Marchena C, Hoel E. (2014). Women's Lives and Challenges: Equality and Empowerment since 2000. Rockville, USA: ICF International

6. National Population Commission and ICF Macro (2009). Nigeria Demographic and Health Survey 2008. National Population Commission and ICF Macro. Abuja, Nigeria.

7. National Population Commission and ICF International (2014). Nigeria Demographic and Health Survey 2013. National Population Commission and ICF International. Abuja, Nigeria, and Rockville, Maryland, USA: NPC and ICF International.

8. Federal Ministry of Women's Affairs and Social Development. (2006). National Gender Policy. Abuja, Nigeria: FMWA\& SD

9. Chowdhary N, Patel V. (2008). The effect of spousal violence on women's health: Findings from the Stree Arogya Shodh in Goa, India. Journal of Postgraduate Medicine. 54 (4):306-312. 
10. Aina O. (2010). Gender Issues and National Response to HIV/AIDS in Nigeria. IPH Technical Series 4. Ile-Ife, Nigeria: Institute of Public Health, Obafemi Awolowo University

11. Population Reference Bureau (2010). Gender-Based Violence: Impediment to Reproductive Health. Retrieved from www.prb.org/igwg_media-impediments-to-RH. pdf, August 5, 2014.

12. World Health Organization (2012). Understanding and addressing violence against women. Retrieved from http:/ /apps.who.int/iris/bitstream/10665/77432/1/ WHO_RHR_1236_eng.pdf, June 25, 2013.

13. Cyril M. (2013). Intimate Partner Violence Prevention in Africa: What Has Been Done and What Still Needs to be Done? Public Health Theses. Paper 301. Retrieved from http://scholarworks.gsu.edu/cgi/viewcontent. cgi?article=1311\&context=iph_theses February 28, 2014. 14. Dutton MA, Green BL, Kaltman SI, Roesch DM, Zeffiro TA, Krause ED. (2006). Intimate Partner Violence, PTSD, and Adverse Health Outcomes. Journal of Interpersonal Violence. 21(7):955-968.

15. Stewart H, Sommerfelt E, Borwankar R, Oluwole D, Fogg K, Goings S. (2010). Domestic violence against women in sub-Saharan Africa: Associations with maternal health. Presented in commemoration of 16 Days of Activism against Gender Violence 2010. Retrieved from www.igwg.org/igwg_media/domestic_violence_presentation.pdf , August 25, 2013

16. Nyamayemombe C, Benedikt C, Mishra V, Gwazane M, Rusakaniko S, Mukweza P. (2010). The Association between Violence against Women and HIV: Evidence from a National Population-Based Survey in Zimbabwe. Zimbabwe Working Papers, No. 4. Calverton, Maryland, USA: ICF Macro.

17. Alio AP, Salihu HM, Nana PN, Clayton HB, Mbah AK, Marty PJ. (2011). Association between intimate partner violence and induced abortion in Cameroon. International Journal of Gynecology and Obstetrics. 112:83-87.

18. Solanke BL. (2014). Association between Intimate Partner Violence and Utilisation of Maternal Health Services in Nigeria. African Population Studies. 28(2, Supplement on Demographic and Health Surveys in Africa):933-945.

19. Bamiwuye SO, Odimegwu C. (2014). Spousal violence in sub-Saharan Africa: does household povertywealth matter? Reproductive Health. Retrieved from http:/ / www.reproductive-health-journal.com/content/11/1/45, September 9, 2014.
20. Kamal SMM. (2012). Domestic Violence, Unwanted Pregnancy and Pregnancy Termination among Urban Women of Bangladesh. Journal of Family and Reproductive Health. 7(1):11-22.

21. Stockl H, Filippi V, Watts, C, Mbwambo JKK. (2012). Induced abortion, pregnancy loss and intimate partner violence in Tanzania: a population based study. BMC Pregnancy and Childbirth. Retrieved from http://www. biomedcentral.com/14712393/12/12, September 10, 2014.

22. Hall M, Chappell LC, Parnell BL, Seed PT, Bewley S.(2014). Associations between Intimate Partner Violence and Termination of Pregnancy: A Systematic Review and Meta-Analysis. Plos Med. Doi:10.1371/journal. pmed.1001581.

23. Garcia-Moreno C, Stockl H. (2013). Violence against Women, Its Prevalence and Health Consequences. In Garcia-Moreno C, Riecher-Rossier A. (eds). Gender Violence and Mental Health. Geneva: World Health Organisation.

24. Heise L, Ellsberg M, Gottemoeller M. (1999). Ending Violence Against Women. Population Reports, Series L, No. 11, Baltimore, Johns Hopkins University School of Public Health, Population Information Program.

25. Kishor S, Johnson K. (2004). Profiling Domestic Violence- A Multi-Country Study. Calverton, Maryland: ORC Macro

26. World Health Organization (2005). WHO MultiCountry Study on Women's Health and Domestic Violence against Women: Summary Report of Initial Results on Prevalence, Health Outcomes and Women's Responses. Geneva: World Health Organization.

27. Hindin MJ, Kishor S, Ansara DL. (2008). Intimate Partner Violence among Couples in 10 DHS Countries: Predictors and Health Outcomes. DHS Analytical Studies No.18. Calverton, Maryland, USA: Macro International Inc.

28. Kishor S, Bradley SEK. (2012). Women's and Men's Experience of Spousal Violence in Two African Countries: Does Gender Matter? DHS Analytical Studies NO. 27. Calverton, Maryland, USA: ICF International.

29. MacQuarrie KLD, Winter R, Kishor S. (2013). Spousal Violence and HIV: Exploring the Linkages in Five Sub-Saharan African Countries. DHS Analytical Studies NO. 36. Calverton, Maryland, USA: ICF International. 30. Tuladhar S, Khanal KR, Lila KC, Ghimire PK, Onta K. (2013). Women's Empowerment and Spousal Violence in Relation to Health Outcomes in Nepal: Further Analy- 
sis of the 2011 Nepal Demographic and Health Surveys. Calverton, Maryland, USA: Nepal Ministry of Health and Population, New ERA, and ICF International 31. Ilika AL. (2005). Women's Perception of Partner Violence in a Rural Igbo Community. African Journal of Reproductive Health. 9(3):77-88.

32. Oyediran KA, Isiugo-Abanihe U. (2005). Perceptions of Nigerian Women on Domestic Violence: Evidence from 2003 Nigeria Demographic and Health Survey. African Journal of Reproductive Health. 9(2): 38-53.

33. Devries KM, Kishor S, Johnson H, Stockl H, Bacchus LJ, Garcia-Moreno C, Watts C. (2010). Intimate partner violence during pregnancy: analysis of prevalence data from 19 countries. Reproductive Health Matters. 18(36):158170.

34. Rahman M (2015). Intimate partner violence and ter- mination of pregnancy: a crosssectional study of married Bangladeshi women. Reproductive Health. 12: 102. Doi: 10.1186/s12978-015-0095-7.

35. Taillieu TL, Brownridge DA (2015). Review: intimate partner violence is associated with termination of pregnancy. Evidence Based Nursing. 18:32. Doi: 10.1136/eb2014-101779.

36. Jansen PA, Holt VL, Sugg NK, Emmanuel I, Critchlow CM, Henderson AD (2003). Intimate partner violence and adverse pregnancy outcomes: A populationbased study. American Journal of Obstetrics and Gynecology. 188: 1341-7.

37. Okenwa L, Lawoko S, Jansson B (2011). Contraception, reproductive health and pregnancy outcomes among women exposed to intimate partner violence in Nigeria. European Journal of Reproductive Health Care. 16(1): 18-25. 